ISSN 2519-7398 (Versión electrónica)

DOI: http://dx.doi.org/10.21704/ac.v78i2.1043

(C) Universidad Nacional Agraria La Molina, Lima - Perú

\title{
Campo y habitus de la metaldad limeña 1994-2014
}

\author{
Field and habitus of metaldad limeña 1994 - 2014
}

Jimmy Renzo Yépez Aguirre ${ }^{1}$

\begin{abstract}
Resumen
Este estudio estuvo orientado a identificar las bondades que tiene el método cualitativo de la teoría fundamentada en los diferentes aspectos del sentir y pensar de los Metaleros de la ciudad de Lima con la finalidad de analizar sus relaciones gregarias ante la sociedad. En tal sentido se planteó los siguientes objetivos: Comprender porque se reproduce la individualización de la vida social, la mercantilización cultural y la fetichización de la música, en el sentir y pensar de los Metaleros de Lima. Se hizo uso de la entrevista a profundidad los que se aplicaron a una muestra no probabilística de 23 jóvenes y adultos metaleros (de 14 a 48 años, como rangos de edad o límites). Se identificó dos categorías conceptuales: La Rockandad y la Metaldad, que sirven para dar la interpretación a la problemática planteada. Y por último se elaboró un instrumento teórico conceptual llamado dialéctica piramidal, para dar paso a la explicación de la investigación realizada.
\end{abstract}

Palabras claves: Individualización; mercantilización; fetichización; rock; metal; habitus; campo; sociedad de consumo.

\begin{abstract}
This study was aimed at identifying the benefits that have the qualitative method of grounded theory on the different aspects of feeling and thinking of the metalheads of Lima in order to analyze their gregarious relations in society. In this regard the following objectives: Understand that reproduces the individualization of social life, cultural commodification and fetishization of music, the feelings and thoughts of the metalheads of Lima. Use of depth interview which was applied to a nonrandom sample of 23 youth and adults metalheads (14 to 48 years as age ranges or limits). The Rockandad and Metaldad, which serve to give the interpretation to the issues raised: two conceptual categories identified. And finally a conceptual theoretical instrument called pyramidal dialectic was prepared to give way to explaining the research.
\end{abstract}

Keywords: Individualization; commodification; fetishization; rock; metal; habitus; field; consumer Society.

\section{Introducción}

El propósito de la investigación fue analizar el devenir de las relaciones gregarias en la reproducción de la vida social, en su construcción del Habitus Metalicus (Bourdieu \& Wacquant, 2005), y las estructuras políticas económicas que las contienen y reproducen, en un ida y vuelta, entre la centralidad europea /norteamericana y la periferia peruana/ limeña.

La investigación se sustenta en la teoría fundamentada, que recoge declaraciones que elaboran los propios Metaleros de la ciudad de Lima, sobre sus vivencias, y el proceso de asimilar una identidad que a la vez es muy criticada, e incomprendida por sus pares y padres, pero a la vez muy satisfactoria y congraciante con ellos mismos, que les brinda otro tipo de desfogue y goce con el ruido, la distorsión, los gritos. Para ello se desarrolló un estudio cualitativo que permitió conocer las principales tendencias del sentir y pensar de los Metaleros de Lima.

Los resultados de la investigación de la tesis, que se subdivide en tres momentos: el primer momento el empírico descriptivo, el segundo momento el interpretativo conceptual y el tercer momento el explicativo teórico. El primer momento analiza empíricamente el sentir y el pensar de los Metaleros de Lima, en su totalidad. El segundo momento interpreta el devenir de los metaleros de Lima a partir de dos categorías la Rockandad y la Metaldad, y por último el tercer momento donde se examina a la luz de un instrumento teórico llamado "dialéctica piramidal" el devenir de las categorías de la Rockandad y la Metaldad.

Para el presente artículo, solamente se extrae una pequeña parte del segundo momento, que es más enfocado a las categorías de Rockandad y Metaldad.

El artículo se divide en cinco partes. La primera sección expone el planteamiento del problema de la investigación. La segunda describe los antecedentes de las investigaciones internacionales y nacionales. Y la tercera presenta la metodología empleada. La cuarta resalta los resultados, de la explicación conceptual de las categorías de la Rockandad y la Metaldad. Finalmente se expone las conclusiones. 


\section{Problema de la investigación}

Considerados como música marginal, subterránea, ahora vemos que la música de tronco metalero, son las raíces históricas y culturales de este proceso de acumulación y desarrollo capitalista financiero y políticamente neoliberal. Para muchos es una relación espuria, bastarda, para otras quizás legitima y auténtica. Esto dio espacio para la investigación y la especulación. Las formas de violencia simbólica muchas veces se concretizan en la complicidad de un receptor pasivo, que ignora el orden de las cosas y por ende el orden del poder, de donde y por quienes emergen dichos modelos, gustos, estéticas, y expresiones que la industria cultural absorbe y reproduce masivamente, segmentadamente, individualisadamente; las relaciones sociales buscan un capital simbólico, para poder diferenciarse y a la vez autentificarse en la variedad del gusto.

Las relaciones de consumo son globales porque su contenido corresponde a un mismo patrón universalizado que se repite en todas partes del mundo y donde el capitalismo mundializado es el principal protagonista. Proceso entendido no como una forma exclusivamente euronorteamericana sino mundial, que tiene su origen en las drásticas alteraciones que experimenta la modernidad, se trata de un proceso de conformación simultanea entre lo global y lo local, en el que concurren las mismas dinámicas de estructuración capitalismo de consumo. La vida social que traza el consumismo en el país representa un componente cardinal de la modernidad global.

Si bien la sociedad de consumo muestra tendencias comunes en todas partes, adopta formas muy diferentes en función del contexto societal y cultural en la que se desarrolla (Mejía, 2014).

Los Metaleros de la ciudad de Lima son parte de un gran movimiento a nivel internacional que se gestó hace 48 años aproximadamente en Inglaterra, y que ahora vemos con mayor presencia en todas las principales ciudades latinoamericanas, y al interior del Perú esta subcultura musical tiene la característica de individualizar aún más la vida social de sus miembros. Los Metaleros están integrados en las principales ciudades, como una minoría presente en la sociedad de consumo de nuestro país, a través de las redes sociales virtuales, entre otros métodos. Para entenderlo de otro modo citaremos a George Yúdice refiriéndose a la expansión del libre comercio y el multiculturalismo:

"Ya dije que el libre comercio ha adoptado el discurso de la diversidad. Y las empresas, ansiosas por legitimar su contribución a la diversidad y por expandirse a nuevos mercados, están auspiciando ex posiciones que versan sobre estos temas y como, consecuencia de ello el ethos multicultural cuenta ahora con un espacio (controvertido) en el mundo del arte Hegemónico. Esto guarda coherencia con el ethos empresarial que se infiltra en todos los aspectos de la vida, aún más en el caso de la privatización promovida por el Neoliberalismo" (Yúdice, 2002).
El movimiento de estas subculturas es más comerciable y más accesible que hace 20 años atrás, donde el acceso a la música estaba centralizado en la ciudad de Lima, en lugares como la "Avenida la Colmena", "Galerías Brasil" y "Quilca", ahora la hegemonía de Internet en el modo de acceso a la música y videos, nos trae un nuevo contexto descentralizado, deslocalizado y muy comercializado y accesible para todos. "Es por esta razón que Frederic Jameson (1984) citado por Gupta \& Ferguson (2008) ha denominado hiperespacio posmoderno ha desafiado tan fundamentalmente la cómoda ficción de que las culturas se hallan situadas en ciertos lugares y corresponden a ciertas agrupaciones humanas". La identidad en los Metaleros es generacional y muy diferenciada, muestra una unidad o cohesión estructural muy heterogénea, cosmopolita, urbana, con rasgos conservadores y liberales, y a la vez, una contradicción que muchas veces fluye, en otras hace corto circuito, y siempre despunta una sobre la otra. "Los jóvenes de hoy tienen facetas habituadas que comprenden cierto grado de identificación, potencialmente contradictorias entre ellas, cuyo conjunto explica la vida de una persona en el contexto social. No hay faceta verdadera o faceta falsa: cada faceta es parte integrante de nosotros, somos esas facetas" (Golte \& León, 2011). La imagen de los Metaleros a través de los medios de comunicación de masas, como la Tv, ha sido estereotipada de una manera burlona, pintoresca, aterradora y desquiciada, haciéndolos ver como desadaptados sociales, de mente insana, con formas de vestir muy llamativas y censurables para la sociedad conservadora de las décadas de los 70 y 80 . Actualmente, esta imagen se ha asumido como natural por parte de la población mundial.

"Ahora, con la aparición de los medios de comunicación de masa - que incidian de manera fuerte entre los jóvenes - no solo se daba un espacio de socialización alterna, sino una oferta continua de nuevas formas de concebir el mundo y la existencia humana que podian chocar con las ideas de las generaciones paternas. Estos conflictos podian resultar fuertes, ya que los institutos de enseñanza ofrecían espacios alternos de reafirmación no solo de una cultura generacional local, sino de hábitos diseminados por los medios de comunicación de masa, como los videojuegos, las películas, las cabinas de internet, la televisión. El escenario para un desdoblamiento de los sujetos se presentaba así. Probablemente esta sea la razón por la cual los jóvenes - en especial aquellos socializados en los años noventa y posteriores - muestran características marcadamente diferentes de las que quienes lo antecedian. Es la generación en la cual el desarrollo de facetas alternas crece y se diversifica, y en la cual aparecen espacios de realización de facetas que no existían de la misma forma para las generaciones precedentes" (Golte \& León, 2011).

La presente investigación tuvo como objetivo desplegar muchos puntos de vistas, opiniones de los mismos metaleros, su percepción, su imaginario, ante las etiquetas, con las cuales a menudo se les asocia, como el satanismo, 
la violencia, la individualidad, las drogas y el alcoholismo. Lo que se trata es de explorar a las subculturas, el rol o la función que estas les brindan, en sus procesos de socialización de imaginarios que ellos mismos asumen, como propios, actitudes y vivencias de los jóvenes que según el INEI (2014) los divide: jóvenes de 15 a 29 años de edad y adultos jóvenes de 30 a 44 años de edad, que viene a ser el grueso de edades donde fluctúan la mayoría de Metaleros. Las características de la música, el entorno, los conflictos, sus gustos, son temas de los cuales desarrollaremos en las siguientes páginas.

\section{Antecedentes:}

La subcultura de los Metaleros es un tema que en la actualidad cuenta con una organización llamada International Society of Metal Music Studies (ISMMS) "Sociedad Internacional para Estudios de Música Metal" fundada en el año 2010; Es una asociación dedicada al estudio de temas relacionados con el Heavy Metal y el Metal Extremo en el ámbito académico, y que busca la investigación, difusión y normalización de estos estudios.

"La misión de ISMMS es fomentar y facilitar la investigación académica trans / interdisciplinarias $e$ internacionales en relación con los procesos y fenómenos relacionados con la música heavy metal y la cultura y para apoyar el reconocimiento de este tipo de investigación como una contribución significativa a las comunidades académicas. Subgéneros del heavy metal y géneros relacionados, por ejemplo, el hardcore punk, están incluidos. ISMMS existe como una organización de coordinación para establecer estudios de música de metal como una disciplina académica relevante y respetada y contribuir al desarrollo del conocimiento dentro de las comunidades académicas y de la música. Estos objetivos se logran a través del desarrollo, la organización y la promoción de la situación de las colaboraciones de arte, publicaciones, actividades y eventos que demuestran altos estándares y principios de la excelencia académica y el objetivo importante de esta investigación en todo el mundo"(ISMMS, 2014).

Está conformada por músicos de Metal y académicos de la cultura de Noruega, Alemania, Suiza, Reino Unido, Francia, Canadá, Nueva Zelanda, Finlandia, Brasil y Estados Unidos. Y la primera conferencia se realizó del 8 al 12 de Junio en el 2015 en Helsinki capital de Finlandia. Como se observa el estudio académico de la subcultura de los Metaleros está concentrada en los idiomas de estos países, particularmente en el idioma inglés, luego el alemán y el francés, las 3 grandes lenguas de la modernidad eurocéntrica y epistémicamente dominantes.

Sin embargo, los estudios o investigaciones que se encuentran en la periferia como el castellano en Latinoamérica y España se presentan con muchos vacíos a modo comparativo. Podemos mencionar algunas investigaciones en Latinoamérica: la tesis en Chile del sociólogo Sánchez (2007) analiza el proceso histórico de cómo llega la subcultura del Metal a Chile. Luego en
Colombia: las sicólogas Maldonado et al. (2008) en la cual se analiza la identidad de los Metaleros, desde una perspectiva de las representaciones sociales, basándose en los aspectos teóricos de la sicología social. En Puerto Rico tenemos la investigación conjunta de los sicólogos Rivera, Mendoza, Varas (2015) donde desarrollan y visibilizan con mayor énfasis una de las manifestaciones más características del género musical metalero como es el mosh.

Y en México: Castillo (2015) en el cual desarrolla desde las herramientas analíticas de la antropología, un buen trabajo donde despliega las explicaciones a los imaginarios, dramas sociales y las ritualidades que se manifiestan en la subcultura Metalera internacional y específicamente en la escena local Metalera de la ciudad de México

\section{Aplicación de la teoría de Bourdieu, P. a la música Rock.}

En España Pérez (2013) hace un análisis sobre la influencia y la aportación que Pierre Bourdieu (1995) hace a la sociología del Rock.

"Podemos adelantar, de acuerdo con (Prior 2011 citado por Pérez, M. 2013), dos usos de la obra de Bourdieu en el análisis sociológico del rock: uno, el más desarrollado hasta finales de los 90, atiende a las dimensiones constitutivas del habitus a partir consumo cultural del rock; este uso es heredero de la lectura e impacto, básicamente, de La Distinción. El otro uso, en ascenso desde el cambio de siglo, atiende a la producción del rock como un campo cultural, y se puede rastrear su impronta en la lectura de Las Reglas del Arte, y en el mundo anglosajón en particular, en la lectura de The Field of Cultural Production. Essayson Art and Literature (recopilación de una serie de artículos que van de finales de los 60 hasta finales de los 80, y que serían la base de Las Reglas del Arte)".

Como se ve Bourdieu está siendo revalorado y sus teorías están siendo aplicadas recientemente al campo cultural de la música Rock. De acuerdo con Prior “....Bourdieu ha fijado la agenda para los estudios post-marxistas sobre las prácticas sociomusicales... sus conceptos de capital cultural, campo y hábitus han sido centrales para la formación de un paradigma crítico en la sociología de la música que demuestre cómo lo social produce, contextualiza o penetra en la música..." (Prior, 2011 citado por Pérez, 2013).

Con este antecedente podemos constatar que la teoría de los campos de producción artística de Bourdieu, está teniendo una aplicabilidad en el análisis del campo de producción cultural en el Rock, es un gran avance que recién se está poniendo en evidencia en estos últimos 10 años.

\section{Estudios de Música Metal en Perú}

En Latinoamérica y en el Perú aun no contamos con trabajos a nivel aplicativo de la sociología de Pierre Bourdieu en el campo de la sociología del Rock; pero tenemos las siguientes investigaciones en Perú, especializados en el 
tema de la subcultura de los Metaleros, tenemos el trabajo de investigación de Boggiano (1991) trabajo que está más focalizado al proceso de comunicación a través de los mensajes de las canciones de algunas bandas de música Metal de Lima. Por otra tenemos el artículo de Monterroso (2006) donde hace un análisis del discurso de la música Metal girando en los ejes del placer y la muerte de manera general y buscando resaltar una autenticidad existencial y a la vez de aspectos simbólicos que cubren el ropaje de la música Metal. También tenemos el artículo de la Tesis de Yépez (2013) en la cual se hace un análisis entre la relación de la política cultural neoliberal y la música Heavy Metal en la ciudad de Huánuco. Un artículo de Yrivarren (2015) donde se desarrolla de manera descriptiva el ambiente y las características que tienen los Metaleros de la ciudad de Lima, mostrándonos la esencia del lugar de los metaleros a la cual la autora llama "el genius loci".

Finalmente, la primera tesis sustentada en Lima sobre los Metaleros para optar el título profesional de licenciada en sicología por Lozada (2016) sobre diferencias de personalidad y salud mental entre Metaleros y no metaleros en Lima.

"El estudio buscó explorar diferencias entre dimensiones básicas de personalidad y de salud mental en personas aficionadas a la música conocida como "metal" (metalero) y los que no lo son (no metaleros) conformado por 106 metaleros y 100 no metaleros entre 18 y 50 años. Tres instrumentos fueron utilizados, uno para evaluar dimensiones básicas de personalidad; y dos para evaluar salud mental (depresión y ansiedad). Los resultados indican que los metaleros suelen ser personas impulsivas y con necesidad de destacar y ser desafiantes; sin embargo, también son personas sociables, demostrando así una relativa mayor estabilidad emocional que el grupo no metalero" (Lozada, 2016).

La subcultura de los Metaleros en Perú se percibe en el campo de la investigación prácticamente como un tema exploratorio y de conocedores, que aun así podemos contar con escasas investigaciones, tesis, monografías, artículos o notas locales. Después tenemos investigaciones más genéricas y abarcativas no focalizadas o especializadas en temas como la subcultura de los Metaleros, sino más históricas y descriptivas que nos hablan del Rock local y sus diferentes ramas o sub estilos, donde se mencionan a los Metaleros, entre las más recientes publicaciones en Lima tenemos la de Yrivarren (2012) Donde hace un mayor énfasis en el aporte urbanístico que pueden dar las tribus urbanas, y al comercio segmentado especializado de lo cual es característico de las tribus urbanas. También tenemos los trabajos de Torres (2012). Donde se hace un recuento histórico de la década de los años 80 pero enfocado a la música subte. Otro autor con más publicaciones al respecto en lo referente a la historia y el proceso descriptivo de Rock peruano es Cornejo (2002) Este es uno de los cuatro libros que tiene donde desarrolla el tema de la música rock peruana. Por otra parte, tenemos a la primera novela Metalera, escrita por el ex - vocalista de la banda de música metal de Lima M.A.S.A.C.R.E, Del Aguila (2012).

Como se puede apreciar a groso modo nuestros autores no profundizaron, ni desarrollaron las temáticas sobre la individualización, mercantilización, la fetichización y la violencia simbólica en las subculturas de los Metaleros de la ciudad de Lima. Esto nos motivó a indagar y a investigar para contribuir a conocer más las realidades de las subculturas en este caso particular la de los Metaleros de Lima; que son parte de esta nueva estructura social peruana que nos hace parte del capitalismo global de consumo.

\section{Matriales y Métodos}

\section{Método}

Tipo de investigación:

La investigación fue de carácter exploratorio, descriptivo e interpretativo. Exploratorio porque examino un tema poco estudiado y descriptivo porque su propósito fue describir la reproducción de la individualización, la mercantilización y la fetichización en el imaginario de los Metaleros. Interpretativo porque sistematizo y explico la articulación de los ciclos y procesos del mercado - individuo - fetiche: Homo - Habitus - Imaginarius.

Instrumentos:

Guía de entrevista a profundidad

\section{Participantes:}

Se tomó una muestra no probabilística intencional o selectivo, de 23 personas lo que permitió acercarnos y garantizar el punto de saturación (Mejía, 2002) para lograr la representatividad científica de la población, dada las características especiales de la unidad de análisis, se tomara en cuenta lo siguiente:

a) Características socio estructurales

- La ciudad de Lima:

- Habitad

- Espacios de encuentro

- Rango de edades

- Sexo

b) Tamaño de la muestra:

- Número de unidades de análisis 02 :

- Metaleros varones (20) $[15$ músicos - 4 fans - 2 negociantes]

- Metaleras mujeres (03) [01 músico - 02 fans]

- Total, de casos: 23

c) Panel de representación de cinco generaciones de Metaleros (Tabla 1).

En el momento apriorístico del proyecto de investigación, se pensó en diferenciar muy marcadamente entre el músico - comerciante - el oyente de la música metal, pero en la práctica se manifestó que estas tres actividades pueden estar yuxtapuestas a la vez, coexisten y habitan en una frontera muy flexible, y se encontró, mucho a músicos y comerciantes a la vez, al igual que oyentes y comerciantes a la vez, en muchos casos se manifiesta una triada en 
espiral, pero que funcionan con lógicas distintas: musicus - comercium - fanaticus.

Tabla 1. Representación de cinco generaciones de Metaleros

\begin{tabular}{|c|c|}
\hline $\begin{array}{l}\text { HOMO ECONOMICUS } \\
\text { METALICUS VARONES }\end{array}$ & $\begin{array}{l}\text { HOMO ECONOMICUS } \\
\text { METALICUS MUJERES }\end{array}$ \\
\hline $1^{\text {era }}$ G: 48-42 años: (1967 - 1973) & $1^{\text {era }} \mathrm{G}: 48-42$ años: $(1967-1973)$ \\
\hline $2^{\text {da }}$ G: 41-35 años: (1974 - 1980) & $2^{\text {da }}$ G: 41-35 años: (1974 - 1980) \\
\hline $3^{\text {era }}$ G: 34-28 años: (1981 - 1987) & $3^{\text {era }}$ G: 34-28 años: (1981 - 1987) \\
\hline $4^{\text {ta }} \mathrm{G}: 27-21$ años: $(1988-1994)$ & $4^{\text {ta }}$ G: $27-21$ años: $(1988-1994)$ \\
\hline $5^{\text {ta }} \mathrm{G}: 20-14$ años: $(1995$ - 2001) & $5^{\text {ta }}$ G: $20-14$ años: $(1995-2001)$ \\
\hline HOMO SOCIOLOGICUS & HOMO SOCIOLOGICUS \\
\hline METALICUS VARONES & METALICUS MUJERES \\
\hline $1^{\text {era }}$ G: 48-42 años: (1967 - 1973) & $1^{\text {era }} \mathrm{G}: 48-42$ años: $(1967-1973)$ \\
\hline $2^{\text {da }}$ G: 41-35 años: (1974 - 1980) & $2^{\text {da }}$ G: 41-35 años: (1974 - 1980) \\
\hline $3^{\text {era }} \mathrm{G}: 34-28$ años: (1981 - 1987) & $3^{\text {era }} \mathrm{G}: 34-28$ años: (1981 - 1987) \\
\hline $4^{\text {ta }}$ G: 27-21 años: $(1988-1994)$ & $4^{\text {ta }}$ G: 27-21 años: $(1988-1994)$ \\
\hline $5^{\text {ta }}$ G: $20-14$ años: $(1995-2001)$ & $5^{\text {ta }}$ G: 20-14 años: $(1995-2001)$ \\
\hline HOMO VIDENS METALICUS & HOMO VIDENS METALICUS \\
\hline VARONES & MUJERES \\
\hline $1^{\text {era }} \mathrm{G}: 48-42$ años: (1967 - 1973) & $1^{\text {era }} \mathrm{G}: 48-42$ años: $(1967-1973)$ \\
\hline $2^{\text {da }}$ G: 41-35 años: (1974 - 1980) & $2^{\text {da }}$ G: 41-35 años: (1974 - 1980) \\
\hline $3^{\text {era }} \mathrm{G}: 34-28$ años: (1981 - 1987) & $3^{\text {era }} \mathrm{G}: 34-28$ años: (1981 - 1987) \\
\hline $4^{\text {ta }}$ G: 27-21 años: $(1988-1994)$ & $4^{\text {ta }}$ G: $27-21$ años: $(1988-1994)$ \\
\hline $5^{\text {ta }} \mathrm{G}: 20-14$ años: $(1995-2001)$ & $5^{\text {ta }}$ G: 20-14 años: $(1995-2001)$ \\
\hline
\end{tabular}

$\mathrm{G}=$ Generación

Tabla 2. Representación de la matriz

\begin{tabular}{|c|c|c|c|c|c|c|c|}
\hline Habitad & $\begin{array}{l}\text { Espacios } \\
\text { de } \\
\text { encuentro }\end{array}$ & Categorías & $\begin{array}{c}\text { Actores } \\
\text { involucrados } \\
\text { en la escena } \\
\text { Metal }\end{array}$ & $\begin{array}{l}\text { Rango } \\
\text { de } \\
\text { edades }\end{array}$ & $\begin{array}{l}\text { Generaciones } \\
(1967-2001)\end{array}$ & Sexo & $\begin{array}{c}\text { Unidad } \\
\text { personas }\end{array}$ \\
\hline \multirow{26}{*}{ Lima } & \multirow{8}{*}{$\begin{array}{c}\text { Galerías } \\
\text { Bares } \\
\text { Conciertos } \\
\text { Parques } \\
\text { Ferias } \\
\text { Salas de } \\
\text { ensayo }\end{array}$} & \multirow{8}{*}{$\begin{array}{l}\text { Homo } \\
\text { Sociologicus } \\
\text { Metalicus }\end{array}$} & \multirow{8}{*}{$\begin{array}{l}\text { Imaginarius } \\
\text { Ideograficus } \\
\text { \& Músicus }\end{array}$} & $48-42$ & Primera & $\begin{array}{c}\mathrm{M} \\
\mathrm{F}\end{array}$ & $\begin{array}{l}1 \\
2\end{array}$ \\
\hline & & & & \multirow{2}{*}{$41-35$} & \multirow{2}{*}{ Segunda } & $\mathrm{M}$ & 3 \\
\hline & & & & & & $\mathrm{F}$ & 4 \\
\hline & & & & \multirow{2}{*}{$34-28$} & \multirow{2}{*}{ Tercera } & $\mathrm{M}$ & 5 \\
\hline & & & & & & $\mathrm{F}$ & 6 \\
\hline & & & & $27-21$ & Cuarta & M & 7 \\
\hline & & & & \multirow{2}{*}{$20-14$} & \multirow{2}{*}{ Quinta } & $M$ & 9 \\
\hline & & & & & & F & 10 \\
\hline & \multirow{10}{*}{$\begin{array}{c}\text { Galerías } \\
\text { Bares } \\
\text { Conciertos } \\
\text { Parques } \\
\text { Ferias } \\
\text { Salas de } \\
\text { ensayo }\end{array}$} & \multirow{10}{*}{$\begin{array}{c}\text { Homo } \\
\text { Economicus } \\
\text { Metalicus }\end{array}$} & \multirow{10}{*}{$\begin{array}{c}\text { Fanaticus, } \\
\text { Commercium } \\
\& \text { Militancia }\end{array}$} & \multirow{2}{*}{$48-42$} & \multirow{2}{*}{ Primera } & M & 11 \\
\hline & & & & & & $\mathrm{F}$ & 12 \\
\hline & & & & \multirow{2}{*}{$41-35$} & \multirow{2}{*}{ Segunda } & M & 13 \\
\hline & & & & & & $\mathrm{F}$ & 14 \\
\hline & & & & \multirow{2}{*}{$34-28$} & \multirow{2}{*}{ Tercera } & M & 15 \\
\hline & & & & & & $\mathrm{F}$ & 16 \\
\hline & & & & \multirow{2}{*}{$27-21$} & \multirow{2}{*}{ Cuarta } & M & 17 \\
\hline & & & & & & $\mathrm{F}$ & 18 \\
\hline & & & & \multirow{2}{*}{$20-14$} & \multirow{2}{*}{ Quinta } & M & 19 \\
\hline & & & & & & $\mathrm{F}$ & 20 \\
\hline & \multirow{8}{*}{$\begin{array}{c}\text { Galerías } \\
\text { Bares } \\
\text { Conciertos } \\
\text { Parques } \\
\text { Ferias } \\
\text { Salas de } \\
\text { ensayo }\end{array}$} & \multirow{8}{*}{$\begin{array}{c}\text { Homo } \\
\text { Videns } \\
\text { Metalicus }\end{array}$} & \multirow{8}{*}{$\begin{array}{l}\text { Violencia } \\
\text { Imaginaria } \\
\text { \& Violencia } \\
\text { Mediática }\end{array}$} & \multirow{2}{*}{$48-42$} & \multirow{2}{*}{ Primera } & $\mathrm{M}$ & 21 \\
\hline & & & & & & $\mathrm{F}$ & 22 \\
\hline & & & & $41-35$ & Segunda & M & 23 \\
\hline & & & & & & $\mathrm{F}$ & 24 \\
\hline & & & & $34-28$ & Tercera & $\underset{F}{M}$ & 25 \\
\hline & & & & $27-21$ & Cuarta & $\mathrm{M}$ & 27 \\
\hline & & & & & & $\underset{\mathrm{F}}{\mathrm{M}}$ & 29 \\
\hline & & & & & Qumta & Total & 1: Treinta \\
\hline
\end{tabular}

d) Panel de representación socio estructurales (Tabla 2).

En un primer momento se planteó la muestra de 15 varones Metaleros y 15 mujeres Metaleras, y en una estratificación correspondiente a generaciones y perfiles de actividad, como ser músico - comerciante - oyente. Y en el caso de las mujeres Metaleras fue difícil empalmar con la lógica muestral diseñada y se trabajó finalmente con 20 Metaleros y 03 Metaleras. Manifestando también la gran representatividad que el género musical siempre estuvo y está inclinado hacia la masculinidad.

\section{Resultados}

\section{Análisis interpretativos}

\section{Campo y Habitus de la Metaldad Limeña:}

\section{Enunciados interpretativos de la música, letras y vestimenta de la Metaldad}

Libres - rebeldes - violentos. Libres en el sonido, rebeldes en las letras, y violentos en la imagen estética, en la ropa. Son tres ingredientes, que pueden ser rotados, como de diferente forma interpretados, libres en la ropa, violentos en el sonido, y rebeldes en las letras.

"La música metal se caracteriza por ser un derivado del hard rock, mucho más estridente, caracterizado por sonidos industriales, metálicos en la batería y distorsiones en la guitarra, dejando por lo general un sitio privilegiado en sus canciones para explorar la destreza de sus músicos en algún solo de guitarra. Las voces van desde las más agudas y melódicas hasta las más guturales y monótonas [...] Y ser metalero no se trata solo de escuchar metal, si no de vivirlo [...] Al preguntar a distintas personas, músicos, aficionados, productores $y$ demás surgieron términos como energía, actitud, pasión, hermandad y militancia. No es solo un estilo musical, es mucho más que eso, es un estilo de vida, comenta con orgullo uno de los asistentes [...] El metal, casi como el futbol, tiene un vínculo directo con la cerveza. Masculinidad en su máxima potencia" (Yrivarren, 2015).

Y si algo caracteriza a la música Metal y a los metaleros es su interés marcado en los temas históricos, la curiosidad de investigar, sobre los temas que sus grupos favoritas cantan, que muchas veces tratan sobre conflictos religiosos, ocultismo, historias medievales, paganismo, mitologías, guerras, nihilismo.

La Metaldad herederos apócrifos de la Rockandad canónica, la Metaldad constituye la herejía refrescante a los nuevos valores de la modernidad tardía. Que se desarrollara globalmente a partir de 1994 hasta el presente. Lo apolíneo y lo dionisiaco, lo convergente y lo divergente, es la meta de la Metaldad, que abrió el proceso de deconstrucción, que paralelamente a él, fluyen las corrientes hegemónicas de lo canónico, de lo convencional, que naturaliza los poderes locales, regionales y globales armonizándolos, como la música de la Rockandad, que es el horizonte expandido 


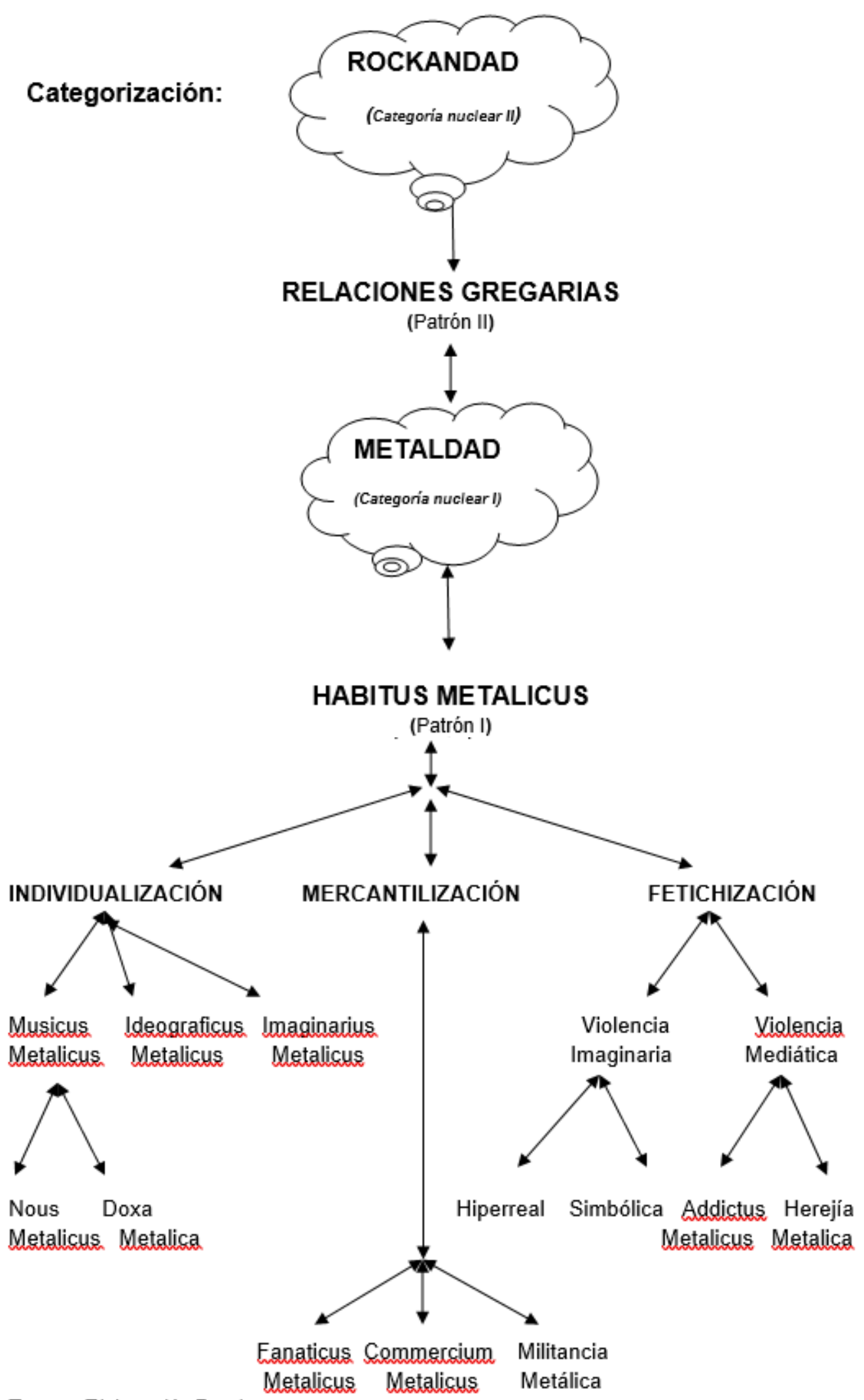

Fuente: Elaboración Propia. 
del poder y sus adversario es la subversión de la Metaldad. "Desde otro nivel de análisis, ha sido también posible determinar las temáticas más frecuentes del Metal, que han sido agrupadas en dos grandes ejes. En esto sigo parcialmente a Weinstein y reformulo alguno de sus ideas que, en general, se puede dar como atinadas. El primero es el vínculo con lo dionisiaco. Es frecuente desde los inicios del Metal el énfasis en el hedonismo y la búsqueda del placer sensorial. En primer término, del placer sexual concreto; luego del placer estético; particularmente por la música de Heavy Metal; y finalmente, el placer ante la victoria, la sensación de triunfo sobre los enemigos [...] La otra gran temática del Metal es la muerte. Weinstein la denomina temática del caos" (Monterroso, 2006).

La libre interpretación, la individualidad en el manejo de la vestimenta de los gustos de los cánones de la Metaldad, que para otros la vestimenta es parte de un proceso de formación, que como tal, se deja de lado, con la interiorización y la comprensión de la música misma. Es donde entra a tallar el habitusmetalicus

\section{Enunciados interpretativos: Artes de la Metaldad}

La música Rock nacida en 1955, en EE.UU. viene hacer como la cristiandad occidental eurocéntrica, (Cristiandad diferenciada del movimiento cristiano, Cristiandad como cosificación del poder de un estado policiaco, coercitivo, acusador, impositivo, como política de estado, creador de estructuras, estructurantes a los sujetos) que colonizo los imaginarios por muchos siglos, en todo el mundo.

El rock reencarna esta nueva cristiandad - secular consumista - creativa, de la cual se desprende la música Metal, que deviene como la reforma protestante del siglo XVI, (para entender la complejidad de la música metal, se tiene que entender la complejidad de la cultura occidental) bajo el luteranismo, anglicanismo, calvinismo, como sus grandes troncos de los cuales brotaran una inmensidad de ramificaciones. Al igual la música Metal, tiene sus grandes troncos: Heavy Metal - Thrash metal - Death metal-Black metal, de los cuales brotan diferentes ramificaciones, sub estilos musicales.

"La cristiandad puede ser el todo social, en su sentido amplio, pero en sentido estricto es un tipo de prácticas eclesiales (por parte de la Iglesia) y de prácticas políticas (por parte del Estado), una cierta manera de estructurar la posición de la Iglesia en el bloque histórico de una determinada sociedad, con todo lo que esto supone en relación con el nivel ideológico, político y aun económico. De otra manera, la Iglesia se ubica en la sociedad politica para efectuar funciones eclesiales en la sociedad civil. Pero aún, y es un aspecto a veces olvidado, es una manera de efectuar las funciones eclesiásticas con respecto al mismo pueblo cristiano; ya que la «sociedad civil» (como momento de la totalidad histórico-concreta) no es idéntica al "pueblo cristiano» (como componente intrínseco de la Iglesia). Lo que pasa es que cuando la totalidad de la sociedad civil es parte de la Iglesia (se ha cristianizado), se tiende a identificar la función de la Iglesia en la sociedad civil (en realidad las «estructuras explícitas» eclesiásticas y eclesiales) con la que realiza con su propio pueblo de laicos. Es evidente que en situaciones límites, como en la iglesia primitiva, donde la Iglesia comenzaba su camino en la historia y la evangelización era su función primordial, el pueblo cristiano era toda la Iglesia y todos los miembros formaban parte de las estructuras explícitas de la Iglesia. En este caso el «pueblo cristiano» (la primitiva Iglesia) se distinguía perfectamente de la sociedad civil del imperio romano. En la cristiandad, por el contrario, como totalidad histórico-concreta, las prácticas eclesiales están regidas por un «modelo» que en sus líneas esenciales sería el siguiente. La estructura eclesiástica jerárquica se sitúa en la sociedad política, es decir, en clara vinculación con los aparatos de Estado. Desde coronar reyes, bendecir ejércitos (ciertos papas hasta los condujeron en los Estados pontificios, que sólo con Garibaldi desaparecieron, en pleno siglo XIX), juzgar a disidentes (función que cumplió la Inquisición en muchos reinos), etc. Es decir, la estructura eclesiástica participaba en funciones de coerción. Pero, en realidad, su función esencial en el «modelo» de cristiandad era más bien, con el apoyo y la fuerza del Estado, cumplir prácticas de creación del consenso en la sociedad civil. De alli que, por lo general, la Iglesia controlaba toda la educación de la sociedad global, produciéndose identidad entre los valores nacionales del grupo y su contenido cristiano [...]

Una última advertencia. Cuando nos referimos a la cristiandad, o cuando demos un juicio negativo sobre ella, débase entender que no es la Iglesia. La cristiandad es un «modelo» o un modo de comprender a la Iglesia en la historia. La Iglesia en cambio es una comunidad institucional y profética, que puede tener en su seno cristianos que tienen diversos «modelos». Y estos últimos no son otra Iglesia o una Iglesia nueva o una Iglesia paralela. Son simplemente miembros de la Iglesia que comprenden a la Iglesia y a sus relaciones con la totalidad histórico-concreta de otra manera, quizá más próxima a la manera como Jesús comprendía a su Iglesia” (Dussel, 1983).

La cristiandad como totalidad cultural europea, como agente de poder colonial, emparentado a los poderes de los reyes, de las monarquías, de los imperios. Aquella función totalizadora, es asumida por la nueva modernidad, por la música Rock, como la nueva cristiandad laica, aquel gran imperio de la totalidad del mercado, la subsunción de aquel estilo musical de raíces de la cultura negra, por el mercado es blanqueado y hegemonizado bajo la etiqueta de música Rock.

Así tenemos el nacimiento de la Rockandad, entendida como un símil a lo que Dussel, y todo el movimiento 
de la modernidad /colonialidad llaman "Cristiandad" diferenciándolo claramente del cristianismo primitivo.

La Rockandad es el proceso histórico, que nace como embrión en 1945, y se desarrolla en las siguientes décadas, es un proceso sumamente acelerado, que tiene como acompañante a las políticas de desarrollo para América latina, y al Estado de Bienestar en Europa, y a la guerra fría con la antigua y desaparecida URSS, como un manto geopolítico en general.

"Desde el cuarto siglo se constituyó la Cristiandad, sistema religioso-cultural de significación política, económica, etc., donde se aunaba la experiencia existencial cristiana con la conceptualización helenística del existir. La Cristiandad latino-occidental de tipo hispano que es la que nos ocupa, vino a América teñida además con las notas propias de la naciente modernidad europea. La Iglesia hispana o latinoamericana es el fruto de ese inmenso proceso que en sus sucesivas etapas fue repitiendo lo ya vivido en el viejo continente. La dominación colonial, la secularización de la vida, al mismo tiempo que la crisis de la modernidad europea, abren un estado imprevisible de cosas" (Dussel, 1972).

La música como en todo proceso histórico, anuncia como aquellos heraldos negros, mensajeros de un nuevo orden político, social. El cambio, la vanguardia, la subversión, el orden. Se encuentra en las formas estéticas y sonoras, que el establishment promueve y a la vez invisibiliza, entre sombras y luces, el proceso de cambio constante, de idas y vueltas se ve reflejado en las estructuras musicales. Si la Rockandad, abre un proceso histórico universal norte europeizante, la Metaldad, es la ramificación, es el sendero luminoso, es la mecha encendida, del proceso de deconstrucción de la Rockandad, aquel proceso que como una bifurcación, lleva a nuevos desarrollos, como la política Neoliberal.

La Metaldad, viene a ser la música Metal, entronada, y subsumida por el mercado, ya sea este subterráneo o informal; es el proceso en el cual, la política neoliberal corre al paralelo con la música Metal, nos referimos específicamente al año 1979, en Inglaterra, donde Margaret Thatcher, asume el neoliberalismo, como política de estado, y la Nueva Ola del Heavy Metal Británico (1979), es lanzado al mundo como mercancía. Por su parte EE.UU. en 1981, asume la presidencia Ronald Reagan, aplica el modelo neoliberal y paralelamente se crea de manera privada MTV (1981), medio que ayudara a difundir y a poner de moda la música Heavy Metal a nivel mundial.

El proceso histórico de la Metaldad, emparentada al Neoliberalismo, en un primer momento, se desarrollara $\mathrm{y}$ visionara al siguiente nuevo proceso que complementa al neoliberalismo, estamos refiriéndonos al proceso de globalización de la década de años 90 .

"Hay que aprender a juzgar una sociedad por sus ruidos, por su arte y por sus fiestas más que por sus estadísticas. Al escuchar los ruidos, podremos comprender mejor adonde nos arrastra la locura de los hombres y de las cuentas, y que esperanzas son todavía posibles [...] La música anuncia, pues es profética. Desde siempre, ha contenido en sus principios el anuncio de los tiempos por venir. Así veremos que si la organización política del siglo XX se arraiga en el pensamiento del siglo XIX, éste está casi completo, en germen, en la música del XVIII.

Y todavía más, la música se ha transformado desde hace veinte años (1955). Esta mutación anuncia las relaciones sociales van a cambiar. La producción material ha cedido ya lugar al intercambio de signos. El show business, el starsystem, el hit parade designan una profunda colonización institucional y cultural. La música está ahí para hacer comprender las mutaciones. Ella obliga entonces a la invención de nuevas categorías, nuevas dinámicas que regeneraran una teoría social hoy día cristalizada, atrapada y moribunda [...] Hay pues que imaginar formas teóricas radicalmente nuevas para hablar de las nuevas realidades. La música, organización del ruido, es una de esas formas. Refleja la fabricación de la sociedad; es la banda audible de las vibraciones y los signos que hacen a la sociedad. Instrumento de conocimiento, incita a descifrar una forma sonora del saber" (Attali, 2011).

La Metaldad, es la industria cultural de la música metal, articulada a los poderes políticos del mercado, es está Metaldad, la que se expande rápidamente a nivel mundial, en la década de los años ochenta, en particular en el Perú, donde se emprende y se desarrolla artesanalmente, en la informalidad, en la piratería, por un lado y en la exclusividad por el otro, para los sectores más acomodados, que pueden adquirir los productos musicales importados Norteamericanos y Europeos, principalmente.

"Hoy día la música, cualquiera que sea el modo de producción del capital, anuncia el establecimiento de una sociedad repetitiva, en la que nada más sucederá, al mismo tiempo que la emergencia de una subversión formidable, hacia una organización radicalmente nueva, nunca antes teorizada, y de la que la autogestión no da más que un débil eco.

En eso la música no es inocente: incuantificable, improductiva, signo puro, hoy día en venta, dibuja a grandes rasgos la sociedad en construcción, en donde lo informal es producido y consumido en serie, en donde la diferencia es recreada artificialmente en la multiplicación de objetos casi idénticos [...]

El arte lleva la marca de su tiempo. ¿Y acaso es por eso una imagen clara? ¿Una estrategia de conocimiento? ¿Un instrumento de lucha? En los códigos que estructuran los ruidos y sus mutaciones, se anuncian una práctica y una lectura teórica nuevas: establecer relaciones entre la historia de los hombres, la dinámica de la economía y la historia del ordenamiento de los ruidos dentro de códigos; predecir la evolución de la una por las formas de la otra, interpenetrar lo económico y lo estético; mostrar que la música es profética y que la organización social es su eco" (Attali, 2011).

Si algo refleja a la sociedad de la modernidad tardía, la 
individualidad, la mercantilización y el fetichismo esa es la música Metal, que en su proceso histórico paralelo al neoliberalismo, nos produce la Metaldad, aquella totalidad cosificada, enmarcada, en lo marginal, en la otredad a la Rockandad, a lo hegemónico establecido, aceptado, a lo canonizado. Esta Metaldad, compuesta por ruidos, disonancias, que alteran la Rockandad, es paso necesario a la reingeniería política de la sociedad de fines de los años 70, en la modernidad tardía de los países avanzados, y posteriormente en la consolidación de la globalización en los años 90. Aquella planificación política solamente se puede ver nítidamente a través del instrumento analítico de la música.

"Mozart o Bach reflejan el sueño de armonía de la burguesía mejor y antes que toda la teoría política del siglo XIX. Hay en las óperas de Cherubini un soplo revolucionario raramente alcanzado en el debate político. Joplin, Dylan o Hendrix, dicen más sobre el sueño liberador de los años sesenta que ninguna teoría de la crisis. Los productos estandarizados de las variedades de nuestros dias, los hit parades y los shows business son las caricaturas, irrisorias y proféticas, de las formas por venir de la canalización represiva del deseo. Esta importancia cardinal de la música en el anuncio de la visión del mundo no es nueva. Para Marx la música es espejo de la realidad; para Nietzsche, palabra de verdad; para Freud, texto a descifrar. Ella es todo eso, porque es uno de los lugares en donde se inician las mutaciones y en donde se segrega la ciencia: [si cerráis los ojos, perdéis el poder de abstraer]. Aun cuando no fuera más que un rodeo para hablar al hombre de la obra del hombre, para escuchar y hacer oir su enajenación, para sentir la inmensidad inaceptable de su futuro silencio, y la amplitud de su creatividad yerma, escuchar la música, es escuchar todos los ruidos y darse cuenta de que su apropiación y su control es reflejo de poder, esencialmente político" (Attali, 2011).

Si la Rockandad, representa la modernidad tardía, esta al principio no fue hegemónica, porque existe un universal mucho mayor, que es la industria cultural como tal, creador y proliferador, de nuevas tendencias, y modas. Esto para la Metaldad, es el enemigo a destruir, si la Rockandad es el momento de la deconstrucción, la industria cultural como tal, madre de todos los universales del consumo, sinfonía del poder dominante, que hace olvidar la violencia en general, y que crea consenso, que armoniza el poder del amo y sus esclavos, del productor y sus consumidores, música que sincretiza, y a la vez hace callar, las quejas de los ciudadanos. La galaxia que engulle y da forma a la pluralidad, heterogeneidad, del mercado, que manifiesta los poderes facticos, es la industria cultural, aquella industria que desarrollo las discotecas, la música comercial, aquello que la Metaldad rehúye, escapa, y le es decadente, porque es el fiel reflejo de la masificación, la imposición de la industria hacia un público pasivo y receptor. Es el mensaje político a flor de piel, lo que ellos aceptan que sea masificado, la canonización de la distracción, y la absolutización del poder dominante de turno.
"Toda música, toda organización de sonidos es pues un instrumento para crear o consolidar una comunidad, una totalidad; es lazo de unión entre un poder y sus súbditos y por lo tanto, más generalmente, un atributo del poder, cualquiera que este sea. Una teoría del poder exige pues actualmente una teoría de la localización del ruido y de su formación. Instrumento de demarcación de su territorio entre los pájaros, el ruido se inscribe, desde sus orígenes, en la panoplia del poder [...] Escuchar, censurar, registrar, vigilar son armas de poder. La tecnología de la escucha, de realización, de transmisión y de grabación del ruido se inscribe en el corazón de este dispositivo. El simbolismo de las palabras congeladas, de las Tablas de la ley, de los ruidos grabados y de la escucha son el sueño de los politólogos y el fantasma de los hombres de poder: escuchar, memorizar, es poder interpretar y dominar la historia, manipular la cultura de un pueblo, canalizar su violencia y su esperanza. ¿Quién no presiente que hoy el proceso, llevado a su extremo límite, está a punto de hacer del Estado moderno una gigantesca fuente única de emisión de ruido, al mismo tiempo que un centro de escucha general? ¿Escucha de qué? ¿Para hacer callar a quién? La respuesta la dan, clara e impecable, los teóricos del totalitarismo: todos ellos, indistintamente, explicaron que es preciso prohibir los ruidos subversivos, porque anuncian exigencias de autonomía cultural, reivindicaciones de diferencias o de marginalidad: la preocupación por el mantenimiento del tonalismo, la primacía de la melodía, la desconfianza con respecto a los lenguajes, los códigos, los instrumentos nuevos, el rechazo de lo anormal, se encuentran en todos esos regímenes, traducciones explicitas de la importancia política de la represión cultural y del control del ruido" (Attali, 2011).

Con esto se podría interpretar porque a los metaleros no les gusta bailar, y es que la Metaldad, no acepta la armonía del poder dominante de la industria cultural identificada con la música comercial, las discotecas, el cortejo, el entendimiento, o la simple no conexión. Y es que las expresiones corporales y emocionales que ellos canalizan, entran en contradicción con la formalidad que representa la modernidad de los bailes convencionales, masificados por los medios de comunicación. Para ello la Metaldad, crea sus propios espacios, y en el Perú, estos espacios son siempre precarios, porque acá se vive artesanalmente, es un Metal primitivo, alejado de la Metaldad, que ofrece grandes escenarios y una industria cultural que lo empuja a hacerse cada vez más grande. En Lima los metaleros se quejan de la falta de profesionalidad, la ausencia de técnicos del sonido, que acompañen a los grupos, mayores lugares, para los cuales poder empoderarse y echar raíces musicales. Si en un principio hubo carencia de instrumentos musicales, en lo contemporáneo, hay abundancia, pero carencia quizás de aquel espíritu de querer ser Metalero hereje, adversario por naturaleza a la música comercial. Pareciera que el sentido de la convergencia y la divergencia que nos propone thomas Piketty (2014) para entender la riqueza y 
su distribución en el mundo están presentes en el proceso de entender realidades como la peruana.

"Hay que desconfiar de todo determinismo económico en este asunto: la historia de la distribución de la riqueza es siempre profundamente política y no podría resumirse en mecanismos puramente económicos [...] La historia de las desigualdades depende de las representaciones que se hacen los actores económicos, políticos y sociales, de lo que es justo y de lo que no lo es, de las relaciones de fuerza entre estos actores $y$ las elecciones colectivas que resultan de ello; es el producto conjunto de todos los actores.

La dinámica de la distribución de la riqueza pone en juego poderosos mecanismos que empujan alternativamente en el sentido de la convergencia y de la divergencia, y que no existe ningún proceso natural y espontaneo que permita evitar que las tendencias desestabilizadoras y no igualitarias prevalezcan permanentemente" (Piketty, 2014).

La convergencia a la que se refiere Piketty (2014), es al conocimiento, a la inversión en la capacitación y formación de habilidades, algo que en general carece la sociedad peruana, y volviendo al particular caso de los Metaleros de Lima, esa carencia en la profesionalidad de técnicos del sonido en vivo, es parchado por la práctica empírica, la informalidad, siguiendo a Piketty la fuerza de divergencia es decir el ensanchamiento y amplificación de las desigualdades se manifiesta y fortalece a la Metaldad de los países desarrollados, donde la convergencia es aprovechada y masificada dando oportunidad para el desarrollo de sus habilidades.

\section{Conclusiones}

La individualización de la vida social de los Metaleros de la ciudad de Lima, gira en tres ejes yuxtapuestos, en formas de espiral entre lo ideal formal - lo real informal precario - y lo ilegal delictivo, que quiere decir; el Metalero de Lima es como el comerciante formal, el ambulante que se la juega o el narco que rompe con la formalidad; (en este caso la formalidad es referida a las costumbres, tradiciones, relacionadas a la libertad delegativa y formativa de los paradigmas y valores institucionales que proporciona la iglesia y los militares).

La escena Metalera limeña, tiene su primer momento, en el segundo gobierno de Fernando Belaunde (1980 - 1985), un primer momento más de oyente, que, de ente activo, es decir había más metaleros, que recién estarían por perfilarse como tal, porque el termino mismo aun estaba en vanguardia, en pleno desarrollo, y los pocos que lo recibían y asimilaban, estaban muy predispuestos a las novedades, porque todo se estaba creando. La Metaldad como industria cultural, se estaba expandiendo y retroalimentando de los diversos campos metalicus que a su vez se generaba con el habitus metalicus, que estructuraba dichos campos metalicus (cuando me refiero a campos metalicus, estoy hablando de los diferentes matices o estilos de la música
Metal, como el Heavy Metal, Thrash Metal, Death Metal, Black Metal, entre otros).

Es a partir del primer gobierno de Alan García (1985 1990), que la Metaldad entra en un segundo momento, a nivel internacional, y este impacto llega hasta América Latina, y al Perú. Si bien la década de los años 80, se la conoce como la década perdida de América Latina, es para la Metaldad, la década prodigiosa, de mucha creatividad, donde los cimientos de la industria se robustecen, y se desprende como un universo aparte, de su progenitor la industria cultural de la Rockandad. Es en este espacio tiempo, que se curva el universo de la Metaldad, y se dirige hacia su propia orbita, hacia su propio campo gravitacional. Mientras tanto en Lima, nacen las pequeñas ebulliciones metálicas, los metaleros que quieren expresar algo, que quieren aportar en su particularidad de ser latinos y limeños. Esta peculiaridad, es minoritaria en el continente sudamericano, todavía, la lógica del homo videns predomina como mayoría, entre los nuevos metaleros. Que quiere decir, que los grupos Metaleros de Lima están fuertemente orientados a copiar, toda esa magia musical que llega de europa y norteamerica, es recién en un tercer momento de la industria cultural de la Metaldad, que en América Latina y en Perú se manifestara en la década de los años 90. ¿Por qué? Por el efecto de la multiculturalidad, y la globalización. Fin de la URSS 1991, los procesos de consolidación de un solo bloque hegemónico EE.UU. están en marcha, hasta consolidarse en 1995 con la OMC (organización mundial del comercio).

Mientras tanto, las políticas hacia la multiculturalidad se hacen más visibles, y esto en el aspecto musical, se refleja por la exaltación de las diversas culturas, un ejemplo práctico para ilustrar esta década y este fenómeno social, es el Black Metal Nórdico, es la exaltación a sus pueblos y culturas originarias pre - cristianas. Esto lo podemos empalmar, con la conquista de América en el siglo XV XVI, Aníbal Quijano, nos da el norte con su constructo tipo ideal de la "colonialidad del poder", para entender la magnitud del legado y persistencia colonial hasta nuestros días, y una de sus formas contemporáneas de manifestación de aquel eurocentrismo, son sus subculturas urbanas musicales, y en particular la música metal, con su andamiaje industrial de la Metaldad.

La Metaldad es el proceso, de aquella acumulación de saberes, europeos y multiculturales, que desdibuja con una mano y con la otra dibuja y organiza nuevas estructuras subjetivas, matizadas siempre entre luces y sombras, entre eros y tanatos.

El gobierno de Alberto Fujimori, es el espacio tiempo (1990 - 2000) en el cual la industria cultural de la Metaldad, se eclipsa, para dar paso a otros estilos musicales, pero a la vez, es el espacio tiempo, que dará cabida, no solamente a las propuestas euro/norteamericanas, sino a la diversidad misma, a la multiculturalidad, sin llegar claro a la interculturalidad. Porque la interculturalidad, se manifiesta de dos maneras, una ideal y una de hecho. Lo ideal sería que se valore, respete, horizontalmente a todas las culturas 
del mundo por igual, pero en el hecho es que siempre hay una cultura hegemónica que subalterniza, a las demás. Y en la industria cultural de la Metaldad, no se escapa de aquel hecho, los mismos campos metalicus, están en constante lucha, por tener el capital cultural, que los diferencie y se desmarquen de sus pares. Los Metaleros de Lima, si bien pertenecen a un espacio tiempo, que tiene su propia orbita gravitacional, sus campos metalicus, por otra son individualistas y esta a la vez genera un comportamiento de onda y de partícula a la vez. Onda, porque mantiene coherente su pensar y sentir metalero, y partícula, porque se desprende, y siempre quiere desmarcarse de sus pares metaleros. Entonces en conclusión podemos decir que los metaleros de Lima, tienen un doble comportamiento ambiguo, por un lado es bueno ser metalero, aunque sea algo extranjero, porque te brinda herramientas para desarrollar tu creatividad artística y por el otro es malo cuando, su imaginario es colonizado totalmente, y no puedo expresar algo propio.

El Metalero es un proceso del Mercado, es un puente, que tiene que ser superado. Porque él está limitado a su finitud, a su ruido, y todo ruido tiene un devenir político y toda política está destinada a cambiar de piel y de música.

\section{Literatura citada}

Attali, J. (2011). Ruidos. Ensayos sobre la economía política de la música. México: Siglo XXI Editores, S.A.

Boggiano, L. (1991). Primera aproximación al fenómeno musical: Heavy Metal, análisis de su contenido y mensaje. (Trabajo de investigación). Lima: Pontificia Universidad Católica del Perú.

Bourdieu, P. \&Wacquant L. (2005). Una invitación a la sociología reflexiva. Buenos Aires: Siglo XXI Editores, S.A.

Bourdieu, P. (1995). Las reglas del arte. Génesis y estructura del campo literario. Barcelona: Editorial ANAGRAMA, S.A.

Castillo, S. (2015). .Música del diablo. Imaginario, dramas sociales y ritualidades de la escena metalera de la ciudad de México. México: Instituto Nacional de Antropología e Historia.

Cornejo P. (2002). Alta tensión: los cortocircuitos del rock peruano. Lima: Emedece Ediciones.

Del Águila, A. (2012). Necio. Lima: Borrador editores S.A.C.

Dussel, E. (1972). Caminos de liberación latinoamericana. (Interpretación histórico - teológico de nuestro continente latinoamericano). Buenos Aires: Latinoamérica Libros.

Dussel, E. (1983). Historia general de la Iglesia en América Latina. Tomo I. España: Ediciones Sígueme, S.A.

Golte, J. \& León, D. (2011). Polifacéticos. Jóvenes limeños del siglo XXI. Lima: IEP - Atoq Editores.
Gupta, A. \& Ferguson, J. (2008). Más allá de la cultura. Espacio, identidad y las políticas de la diferencia. Traducción de Erna von der Walde. Antipoda, $N^{\circ} 7$, Julio - Diciembre 2008, 233 - 256.

INEI (2014). Lima tiene 8 millones 693 mil 387 habitantes. Recuperado de http://archivo.larepublica.pe/1701-2014/inei-lima-tiene-8-millones-693-mil-387habitantes Consultado el 29/06/14

International Society of Metal MusicStudies - ISMMS (2014). Recuperado de http://www.ucmo.edu/ metalstudies/metal_studies_home.html. Consultado el 17/04/14

Lozada, N. (2016). Diferencias de personalidad y salud mental entre metaleros y no metaleros de Lima. (Tesis para optar el título profesional de licenciatura en psicología no publicada) Lima: USIL.

Maldonado, V. et al. (2008) Representaciones sociales hacia una cultura del Metal, de un grupo de Metaleros de Bogotá. Artículo de Tesis publicado en la revista Diversitas. Perspectivas en psicología, 5 (1): 111124. Bogotá: Universidad Santo Tomás. Recuperado de http://www.redalyc.org/pdf/679/67916259010.pdf. Consultado el 18/04/14.

Mejía, J. (2002). Problemas metodológicos de las ciencias sociales en el Perú. Lima: Fondo Editorial de la UNMSM. Facultad de Ciencias Sociales.

Mejía, J.(2014). Sociedad, consumo y ética. El Perú en tiempos de globalización. Lima: Fondo Editorial de la UNMSM. Facultad de Ciencias Sociales.

Monterroso, C. (2006). La defensa de la autenticidad: el placer y la muerte en el discurso del Heavy Metal. En: Anthropia revista de antropología y otras cosas. 4: 39 - 45. Lima: PUCP.

Pérez, M. (2013). La obra de Bourdieu como marco de análisis sociológico del Rock. Recuperado de http:// musyca.es/la-obra-de-bourdieu-como-marco-deanalisis-sociologico-del-rock/.

Piketty, T. (2014). El capital en el siglo XXI. México: Fondo de Cultura Económica.

Rivera, E. \& Mendoza, S. \& Varas, N. (2015). Entre el orden y el caos: el papel del mosh en la comunidad metalera de Puerto Rico. En revista de ciencias sociales, 28: 104 -121. Recuperado de http://revistas.upr.edu/index.php/ rcs/article/view/5059.

Sánchez, M. (2007). Thrash Metal: del sonido al contenido, origen y contenido de una contracultura. Tesis de Licenciatura en Sociología. Chile: Universidad de Chile. Recuperado de https://www.academia. edu/4005916/Thrash_metal_del sonido_al contenido.

Torres, C. (2012). Se acabó el show. 1985, el estallido del rock subterráneo. Lima: Editorial Mutante.

Yépez, J. (2013). Política cultural neoliberal y la música Heavy Metal en la ciudad de Huánuco, Perú 1990 2010. Artículo de Tesis publicado En: Revista de Investigaciones Sociales, 17 (30): 279 - 290. Lima: 
Universidad Nacional Mayor de San Marcos.

Yrivaren, S. (2015). El ginius loci del Metal en Lima. En: Romero, R. [Editor] Música popular y sociedad en el Perú contemporáneo. Lima: IDE - PUCP pp. 282 - 301.

Yrivarren, S. (2012). Tribus Urbanas en Lima. Jóvenes y Adolescentes en busca de un espacio en la ciudad, 1990-2010. Lima: Arquitectura de Bolsillo - PUCP.

Yúdice, G. (2002). El recurso de la cultura. Usos de la cultura en la era global. Barcelona: Editorial Gedisa. S.A. 